\title{
Association of Vitamin D Levels with the Metabolic Profile and Sexual Maturation Stage of Adolescents
}

\author{
Jesselina Francisco Dos Santos Haber'1, Karina Quesada1, Renata Nunes Lopes', \\ Daniela Oliveira Silva1, Juliana Medeiros Silva', Sabrina Antonelli Cardoso', \\ Thiago Fernando Luz¹, Cláudia Rucco Penteado Detregiachi', Sandra Maria Barbalho1,2* \\ ${ }^{1}$ Department of Nutrition and Biochemistry, School of Medicine, University of Marília (UNIMAR), São Paulo, Brazil \\ ${ }^{2}$ Departme of Biochemistry and Nutrition, Faculty of Food Technology of Marília (FATEC), São Paulo, Brazil \\ Email: *smbarbalho@gmail.com
}

How to cite this paper: Haber, J.F.D.S., Quesada, K., Lopes, R.N., Silva, D.O., Silva, J.M., Cardoso, S.A., Luz, T.F., Detregiachi, C.R.P. and Barbalho, S.M. (2018) Association of Vitamin D Levels with the Metabolic Profile and Sexual Maturation Stage of Adolescents. Journal of Diabetes Mellitus, 8, 114-124

https://doi.org/10.4236/jdm.2018.84011

Received: August 15, 2018

Accepted: October 7, 2018

Published: October 10, 2018

Copyright $\odot 2018$ by authors and Scientific Research Publishing Inc. This work is licensed under the Creative Commons Attribution International License (CC BY 4.0).

http://creativecommons.org/licenses/by/4.0/

cc) (i) Open Access

\begin{abstract}
The deficiency of Vitamin D (VD) is widely prevalent worldwide in adults, but many studies show that this deficiency also affects adolescents and may be considered a global public health problem. The VD levels are particularly significant in adolescents since it influences several aspects of growth, development, and puberty. During this phase of life, both girls and boys develop reproductive aspects, and secondary sexual characteristics and the adequate nutritional status appear to be the prerequisite for normal pubertal development. Due to the importance of VD in adolescents, the objective of this study was to investigate the association of the levels of this vitamin with glycemic, lipid, and anthropometric profile and sexual maturation stages of adolescents. Anthropometric (weight and height) and biochemical (fasting glycemia, total cholesterol, HDL-c, LDL-c, and triglycerides) data and VD levels were collected in 67 adolescents. $66 \%$ of the adolescents showed VD sufficiency, $28 \%$ insufficiency, and $6 \%$ showed the deficiency. There was a significant difference in VD levels between the stages of sexual maturation for boys and girls. Overweight patients had lower serum VD levels. The correlation analysis indicated a positive correlation between VD and fasting glycemia and HDL-c, but with no significant difference. A negative correlation was observed between VD and cholesterol, LDL-c and triglycerides, but also with no significant difference. Once VD is crucial for bone health, and as it seems it is necessary to the homeostasis of glycemia, lipids, and body weight, we suggest that more studies should be conducted to confirm the precise role of this vitamin in the promotion and maintenance of health in this population.
\end{abstract}




\section{Keywords}

Adolescents, Vitamin D, Glycemia, Lipids, Obesity

\section{Introduction}

Vitamin D (VD) is a fat-solublehormone that can be obtained from the diet or is synthesized in the skin under sunlight exposition. When produced in the skin, the 7-dehydrocholesterol undergoes activation by ultraviolet light, and further modifications occur in kidney and liver to produce VD3 (1,25-dihydroxyvitamin $\mathrm{D}_{3}\left(1,25(\mathrm{OH})_{2} \mathrm{D}_{3}\right)[1][2]$.

In addition to being involved in skeletal health and calcium and phosphate homeostasis, VD also exhibits other essential functions, and its deficiency has been associated with altered insulin secretion, insulin resistance, type 2 diabetes (DM), obesity, dyslipidemia, high blood pressure and cardiovascular diseases [3] [4] [5].

The deficiency of VD is widely prevalent worldwide in adults, but many studies show that this deficiency also affects children and adolescents and may be considered a global public health problem [6]. Low VD status is related to the way of life of modern communities leading people to spend most of their time indoors and without sunlight exposition [7].

The VD levels are particularly significant in adolescents since it influences several aspects of growth, development, and puberty. During this phase of life, both girls and boys develop reproductive aspects, and secondary sexual characteristics and the adequate nutritional status appear to be the prerequisite for normal pubertal development [8] [9].

Due to the importance of VD in adolescents, the objective of this study was to investigate the association of the levels of VD with the glycemic, lipid, and anthropometric profile and sexual maturation stages of adolescents.

\section{Methods}

This study is primary, analytical, observational, transversal, retrospective, quantitative and exploratory. The study population was composed of adolescents attending a Pediatric Center, located in the city of Marília, SP, Brazil.

We selected 67 patients who met the inclusion criteria: adolescents 10 to 19 years old, both sexes, who presented in the medical record, the results of the parameters required in our research. The exclusion criteria were patients presenting liver or renal diseases, resection of the jejunum, diseases that promote biliary flow alterations (cholestasis, decrease in the enterohepatic circulation of bile salts), non-absorbent diseases (celiac disease, Crohn's disease, short bowel syndrome), lupus erythematosus, hypo or hyperthyroidism, and patients that were ingesting vitamin supplements.

Anthropometric data (weight and height), VD levels, fasting glycemia, total 
cholesterol, HDL-c, LDL-c, and triglycerides were collected. The classification of the stages of sexual maturation and the anthropometric data were previously collected and evaluated by the physician responsible for the Pediatric Center and subsequently recorded in the patient's chart. The nutritional state was evaluated according to the Body Mass Index/Age (Z Score). For the stage of sexual maturation, stage 1 corresponds to pre-pubertal development and growth, whereas stages 2 to 4 correspond to the progression from puberty to full maturation, and stage 5 includes the finalization of the sexual maturation [10].

As for the stage of sexual maturation, the adolescents were classified according to the Tanner criteria by medical evaluation and later they were grouped in three pubertal stages: Stage Tanner I (pre-pubertal); stage II - IV (pubertal) and stage $\mathrm{V}$ (post-pubertal). In this study, the adolescents were only in the pre-pubertal and pubertal stages.

VD wasclassifiedaccordingtoHolick et al. [11]. Value for sufficiency was 30 $100 \mathrm{ng} / \mathrm{mL}$; insufficiency was $21-29 \mathrm{ng} / \mathrm{mL}$; deficiency was less than $20 \mathrm{ng} / \mathrm{mL}$, and toxicity was higher than $100 \mathrm{ng} / \mathrm{mL}$.

Approval for the execution of this study was provided by the Research Ethics Committee (University of Marilia, UNIMAR) under Protocol number 2,083,552 on $05 / 25 / 2017$.

The statistical treatment of the quantitative data was performed with the support of the Bio Estat 5.0 program (Significance level of 5\%). Test $\mathrm{T}$ of independence, Mann-Whitney, Anova 1 criteria and Pearson Correlation were used to study the parameters.

\section{Results}

The sample consisted of 67 adolescents (52.24\% were female and $47.76 \%$ male). Regarding the classification of nutritional status according to BMI/AGE, 1.49\% presented thinness, $52.24 \%$ presented eutrophy, $22.39 \%$ were overweight, and $23.88 \%$ presented obesity. Short stature for age was found in $2.99 \%$, and $97.01 \%$ presented adequate height for age. The adolescents showed a mean body weight of $48.57 \pm 13.96 \mathrm{~kg}$. Body mass index (BMI) is shown in Table 1. This table also shows the results for VD levels and biochemical parameters.

According to the guidelines of VD, $66 \%$ of the adolescents showed VD sufficiency, $28 \%$ insufficiency, and $6 \%$ showed a deficiency. Test $\mathrm{T}$ indicated that there was no significant difference between VD levels in girls and boys.

There was a significant difference in VD levels between the stages of sexual maturation $(\mathrm{p}<0.0001)$ for both males and females, as can we observe in Table 2.

Table 3 shows that the nutritional status of adolescents according to BMI/age interferes with serum VD levels, indicating a significant difference between them. Furthermore, overweight patients had lower serum VD levels. When comparing the distribution of VD levels and BMI/age in girls, there was no significant difference. However, when compared to boys, VD levels and BMI/age presented a significant difference, as can be observed in Table 3. 
Table 1. Age, body weight, BMI, Vitamin D, anthropometricand biochemicalparameters of the studied adolescents.

\begin{tabular}{ccccccc}
\hline \multirow{2}{*}{ Parameters } & \multicolumn{2}{c}{ Total of adolescents } & \multicolumn{2}{c}{ Girls } & \multicolumn{2}{c}{ Boys } \\
\cline { 2 - 7 } & Mean \pm SD & Median & Mean \pm SD & Median & Mean \pm SD & Median \\
\hline Age (months) & $144.24 \pm 17.76$ & 139.00 & $139.46 \pm 17.76$ & 137.00 & $149.47 \pm 20.40$ & 140.50 \\
Weight (kg) & $48.57 \pm 13.96$ & 46.50 & $45.27 \pm 11.84$ & 43.30 & $52.18 \pm 15.34$ & 53.50 \\
BMI (kg/m $)$ & $20.68 \pm 3.85$ & 20.08 & $20.27 \pm 4.13$ & 18.79 & $21.13 \pm 3.52$ & 20.58 \\
Vitamin D (ng/mL) & $33.66 \pm 7.94$ & 33.40 & $32.82 \pm 7.58$ & 31.70 & $34.57 \pm 8.35$ & 34.87 \\
Fasting blood glucose & $90.27 \pm 7.83$ & 89.50 & $90.84 \pm 6.84$ & 91.00 & $89.67 \pm 8.84$ & 88.00 \\
(mg/dL) & $166.27 \pm 31.50$ & 162.00 & $172.84 \pm 35.30$ & 166.00 & $159.09 \pm 25.38$ & 159.65 \\
Total cholesterol (mg/dL) & $97.64 \pm 24.02$ & 96.60 & $102.77 \pm 26.67$ & 100.90 & $92.04 \pm 19.66$ & 92.00 \\
LDL-c (mg/dL) & $51.53 \pm 11.92$ & 51.00 & $52.29 \pm 14.73$ & 51.00 & $50.69 \pm 7.94$ & 51.50 \\
HDL-c (mg/dL) & $82.38 \pm 37.51$ & 75.00 & $85.50 \pm 38.31$ & 78.00 & $78.95 \pm 36.92$ & 71.00 \\
Triglycerides (mg/dL) & & & & &
\end{tabular}

BMC: Body Mass Index.

Table 2. Comparison of age, anthropometric and biochemical parameters in different stages of sexual maturation in girls and boys.

\begin{tabular}{|c|c|c|c|c|c|}
\hline Parameters & \multicolumn{2}{|c|}{ Pre-pubertal $(n=7)$} & \multicolumn{2}{|c|}{ Pubertal $(n=28)$} & \multirow[t]{2}{*}{$\mathrm{p}$-value } \\
\hline Girls & Mean \pm SD & Median & Mean \pm SD & Median & \\
\hline Age (months) & $137.25 \pm 13.88$ & 134.00 & $148.28 \pm 7.73$ & 149.00 & 0.0177 \\
\hline $\operatorname{BMI}\left(\mathrm{kg} / \mathrm{m}^{2}\right)$ & $21.85 \pm 5.75$ & 22.00 & $19.14 \pm 3.57$ & 18.00 & 0.0616 \\
\hline Vitamin D (ng/mL) & $22.57 \pm 3.82$ & 24.00 & $34.89 \pm 6.02$ & 34.00 & $<0.0001^{\star}$ \\
\hline $\begin{array}{l}\text { Fasting blood glucose } \\
\qquad(\mathrm{mg} / \mathrm{dL})\end{array}$ & $89.28 \pm 5.46$ & 92.00 & $90.90 \pm 6.96$ & 90.00 & 0.2867 \\
\hline Total cholesterol (mg/dL) & $183.85 \pm 31.74$ & 179.00 & $169.96 \pm 36.14$ & 161.50 & 0.1798 \\
\hline $\mathrm{LDL}-\mathrm{c}(\mathrm{mg} / \mathrm{dL})$ & $105.42 \pm 24.22$ & 102.00 & $101.78 \pm 27.84$ & 99.00 & 0.3767 \\
\hline HDL-c (mg/dL) & $55.42 \pm 9.58$ & 54.00 & $51.28 \pm 15.82$ & 49.00 & 0.2573 \\
\hline Triglycerides $(\mathrm{mg} / \mathrm{dL})$ & $107.57 \pm 57.48$ & 87.00 & $79.82 \pm 30.85$ & 71.00 & $0.0381^{*}$ \\
\hline Parameters & \multicolumn{2}{|c|}{ Pre-pubertal $(n=7)$} & \multicolumn{2}{|c|}{ Pubertal $(n=25)$} & p-value \\
\hline Boys & Mean \pm SD & Median & Mean \pm SD & Median & \\
\hline $\operatorname{BMI}\left(\mathrm{kg} / \mathrm{m}^{2}\right)$ & $22.42 \pm 4.03$ & 23.00 & $20.04 \pm 3.27$ & 20.00 & 0.0573 \\
\hline Age (months) & $139.71 \pm 11.96$ & 141.00 & $152.20 \pm 21.59$ & 140.00 & 0.1635 \\
\hline Vitamin D (ng/mL) & $22.57 \pm 2.63$ & 23.00 & $37.36 \pm 6.19$ & 36.00 & $<0.0001^{\star}$ \\
\hline $\begin{array}{l}\text { Fasting blood glucose } \\
\qquad(\mathrm{mg} / \mathrm{dL})\end{array}$ & $88.57 \pm 7.20$ & 86.00 & $89.80 \pm 9.32$ & 88.00 & 0.3751 \\
\hline Total cholesterol (mg/dL) & $166.28 \pm 37.55$ & 165.00 & $156.96 \pm 21.38$ & 159.00 & 0.3161 \\
\hline LDL-c (mg/dL) & $98.14 \pm 28.10$ & 94.00 & $90.00 \pm 16.86$ & 89.00 & 0.1699 \\
\hline HDL-c (mg/dL) & $47.57 \pm 6.13$ & 44.00 & $51.44 \pm 8.20$ & 53.00 & 0.1285 \\
\hline Triglycerides (mg/dL) & $98.85 \pm 56.78$ & 84.00 & $73.20 \pm 28.41$ & 69.00 & 0.1635 \\
\hline
\end{tabular}

BMI: Body Mass Index; ${ }^{\star}$ Level of Significance: $\mathrm{p} \leq 0.05$. 
Table 3. Vitamin D levels and BMI classifications.

\begin{tabular}{|c|c|c|c|c|c|}
\hline Parameters & Underweight $(\mathrm{n}=1)$ & Normal $(\mathrm{n}=35)$ & Overweight $(\mathrm{n}=15)$ & Obese $(\mathrm{n}=16)$ & p-value \\
\hline All & \multicolumn{5}{|c|}{ Mean \pm SD } \\
\hline Vitamin D (ng/mL) & 49.66 & $34.87 \pm 7.87$ & $28.84 \pm 7.60$ & $34.51 \pm 6.21$ & $0.0302^{*}$ \\
\hline Variables & Underweight $(\mathrm{n}=0)$ & Normal $(n=20)$ & Overweight $(\mathrm{n}=9)$ & Obese $(n=6)$ & p-value \\
\hline Girls & \multicolumn{5}{|c|}{ Mean \pm SD } \\
\hline $\begin{array}{c}\text { Vitamin D } \\
(\mathrm{ng} / \mathrm{mL})\end{array}$ & 0 & $34.15 \pm 7.52$ & $29.88 \pm 8.19$ & $30.50 \pm 5.75$ & 0.3083 \\
\hline Variables & Underweight $(\mathrm{n}=1)$ & Normal $(n=15)$ & Overweight $(\mathrm{n}=6)$ & Obese $(n=10)$ & p-value \\
\hline Boys & \multicolumn{5}{|c|}{ Mean \pm SD } \\
\hline $\begin{array}{c}\text { Vitamin D } \\
(\mathrm{ng} / \mathrm{mL})\end{array}$ & 49.66 & $34.80 \pm 8.64$ & $26.33 \pm 6.53$ & $36.30 \pm 5.35$ & $0.0339^{*}$ \\
\hline
\end{tabular}

BMI: Body Mass Index. ${ }^{\star}$ Level of Significance: $\mathrm{p} \leq 0.05$.

When the variables were correlated (Figure 1) the data show a positive correlation between VD and fasting glycemia and between VD and HDL-c, but without significant difference. Serum levels of VD and their correlations with cholesterol, LDL-c, and triglycerides were negative, but also with no significant difference. The sample was divided by sex for the correlation of the variables, but all the results did not show a significant difference.

\section{Discussion}

In this study, we evaluated the association between VD levels with anthropometric and biochemical parameters and pubertal stage of adolescents. According to our results, overweight was present in $46.27 \%$, and $34 \%$ presented VD deficiency or insufficiency. The VD values were statistically different according to the nutritional status of the BMI/age index, and reduced levels were observed in overweight patients.

Deficiency of VD is observed worldwide at any age. According to Saggese et al. [12], the prevalence of VD deficiency ranges from $9 \%$ to $18 \%$, and hypovitaminosis may reach $51 \%$ to $61 \%$. A meta-analysis with almost 15,000 European pediatric patients showed that the deficiency might reach $4 \%$ to $7 \%$ in children with 1 - 6 years; $1 \%$ to $8 \%$ in $7-14$ years, and $12 \%$ to $40 \%$ in $15-18$ years. Authors suggested that particular attention should be directed to infants and adolescents. These data are similar to our results. The pre-pubertal period is the phase that precedes puberty, and it is associated with accumulation of adipose tissue as a form of energy storage for later growth. As the VD is associated with adipose tissue, its levels may be modified at this stage of life [13].

Other authors also showed that VD is associated with obesity in adolescents. It is still not clear if the reduced levels of VD trigger or are a consequence for obesity. However, the increase in the adipose tissue is a factor that may be related with the reduction of VD in the pubertal stage. The association of VD and adipose tissue may occur due to the capacity of this tissue for storage of lipophilic 


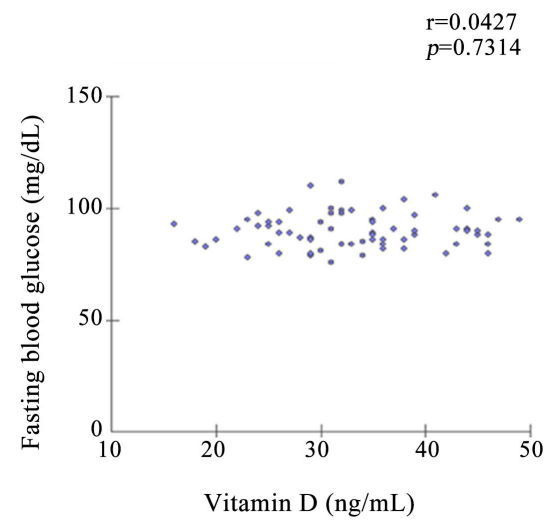

(a)
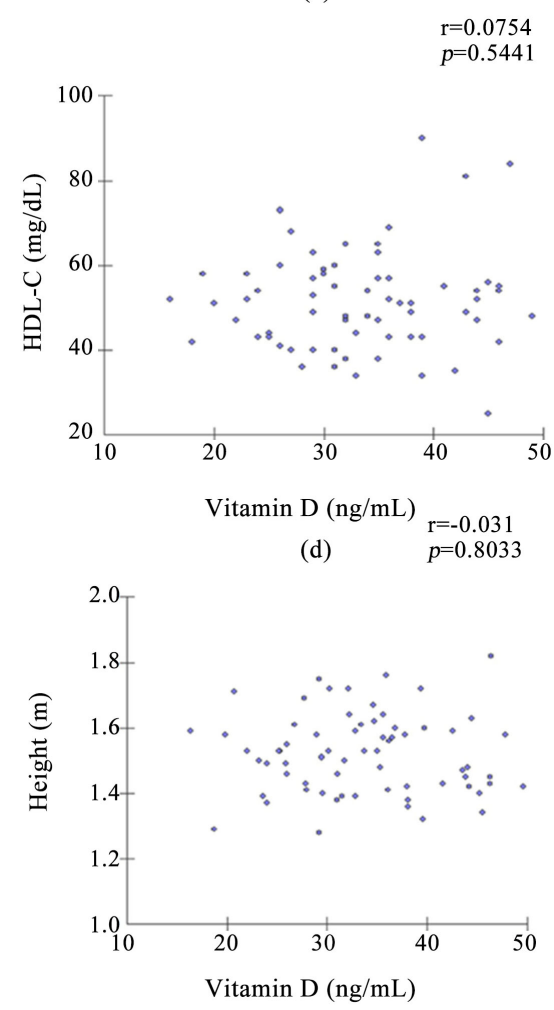

(g)

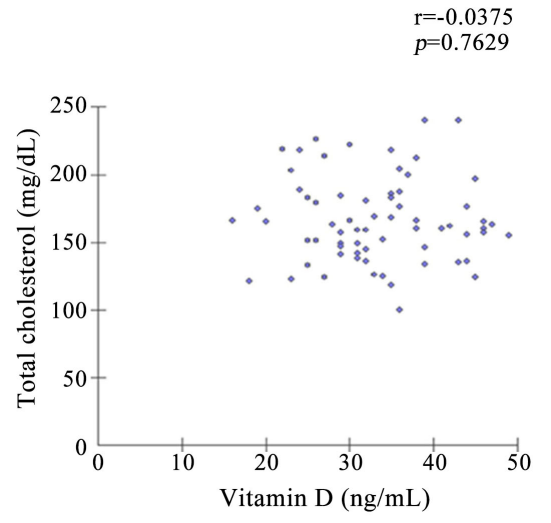

(b)

$\mathrm{r}=-0.2100$
$p=0.0879$

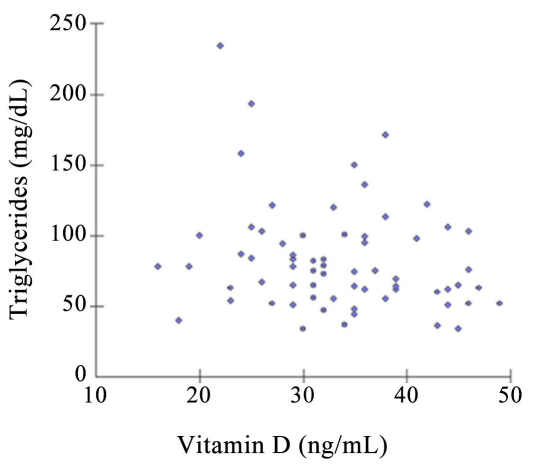

(e)

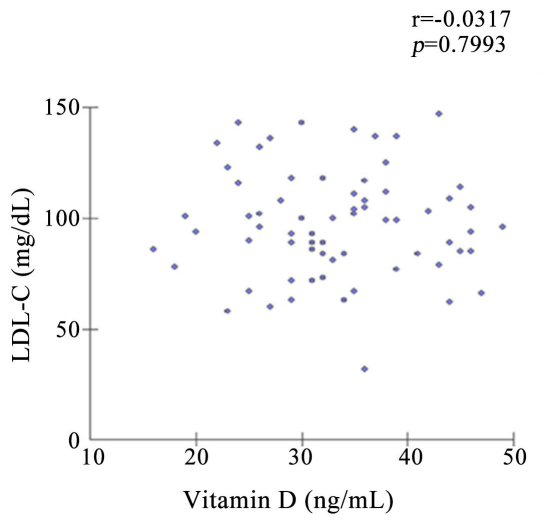

(c)

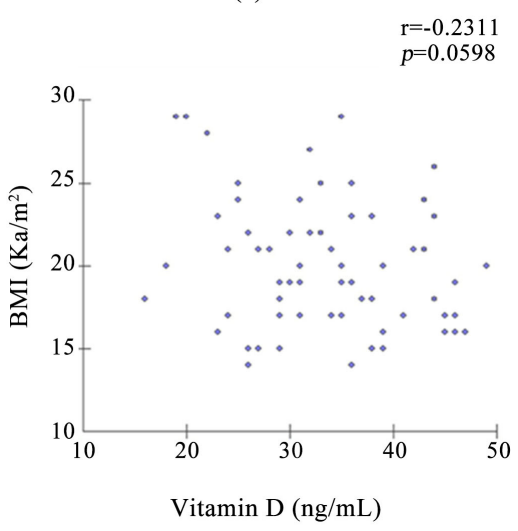

(f)

Figure 1. Correlation of serum vitamin D levels with (a) fasting glycemia; (b) total cholesterol; (c) LDL-c; (d) HDL-c; (e) triglycerides; (f) BMI; (g) height. Data evaluated by Pearson Correlation.

substances. This association has been shown by several authors regardless of age and latitude [14] [15] [16] [17].

On the other hand, the reduction of body weight barely improves VD status compared with the maintenance of weight under the same VD intake. Furthermore, studies with adult patients showed that the supplementation with this vitamin could not reduce adiposity. These findings show that hypovitaminosis D does not necessarily lead to obesity [12] [18] [19].

In adolescents, hypovitaminosis $\mathrm{D}$ is also related to defective bone mineralization [20], increases the risk of urinary and respiratory infections, tuberculosis [21] [22], allergies [12] [23], asthma [24], celiac disease [25], inflammatory bo- 
wel diseases [26], type 1 diabetes [27], obesity and metabolic syndrome [28].

VD also interferes with the secretion of insulin and affects the glycemia. This relationship with the development of diabetes is a serious worry once high levels of plasmatic glucose is related to other components of the metabolic syndrome, thus, increase the risk of cardiac issues in late stages of life [29] [30]. Thorsen et al. [31] also showed that maternal or neonatal levels of VD display a clinically significant effect on the risk of developing type 1 diabetes in childhood.

On the other hand, Brar et al. [15] used a high dose of VD in obese adolescent and did not find improvement on insulin secretion and sensitivity, and concluded that this supplementation did not appear to produce benefits on the homeostasis of the glucose on obese adolescents. Savastano et al. [32] and Gul et al. [33] found a negative correlation between VD levels and fasting glycemia.

The role of hypovitaminosis $\mathrm{D}$ in worsening the comorbidities in adolescence is, furthermore, related to the lipoprotein metabolism. Obese children with insufficiency of this vitamin exhibit a higher risk for reduced levels of HDL-c and hypertension [34]. Although without significance, our results showed a positive correlation between VD and HDL-c levels. Sriram et al. [34] and Prodam et al. [35] showed that VD levels are negatively correlated with total cholesterol, LDL-c, and triglycerides, corroborating our findings. VD receptors (VDRs) are found ubiquitously, including the adipose tissue. These receptors are related to the cholesterol levels by regulating bile acid synthesis. Studies on animal models and humans suggest that VDRs inhibit the expression of receptors, which usually acts indirectly by decreasing the expression of CYP7A1, a limiting enzyme in bile acid synthesis, increasing cholesterol levels.

Contradicting recent studies that have shown that supplementation with VD may improve glycemia and lipid profile in children with deficiency of this vitamin [36] [37] [38], Jamka et al. [39] and Jamka et al. [40] performed meta-analysis that showed no correlation between VD and glucose and lipid levels.

The stage of pubertal development affects the body composition in both sexes [41]. Although Fernández et al. [8] concluded that in the pubertal stage the children exhibited values significantly lower of VD than prepubescent children, our results indicate that when the sample is divided by stages of sexual maturation (pre-pubertal and pubertal stage), there is a significant difference in the serum levels of VD and BMI. This could be explained because lower serum value of this vitamin, also associated to greater adiposity, are present in the period of development and growth (pre-pubertal) when compared to the progression of puberty (pubertal).

Skin can synthesize most of the VD requirements (90\%) due to the exposition of ultraviolet $\mathrm{B}$ radiation from the sunlight. Notwithstanding, this production may be influenced by latitude, season, skin pigmentation, time and area of exposure. During periods of less exposition to sun, the endogenous stores may provide the needs for this vitamin or supplementation should be performed [42]. As adolescents are in a critical phase of growth, bone formation and develop- 
ment, the need for this vitamin is higher during puberty. Furthermore, this population is at augmented risk for deficiency of VD, and some authors recommend continuous supplementation in addition to the VD obtained from the diet or produced due to the exposition to the sunlight [43] [44].

Similarly to many other studies, our data suggest that adolescents are at higher risk of VD deficiency and insufficiency, mainly the obese. VD concentrations, BMI, and triglyceride values differed at puberty, with levels of this vitamin and higher adiposity during the pre-pubertal stage. As the role of this vitamin in the biochemical and anthropometric profile is not well established, we suggest that further studies are necessary to the standardization of supplementation in controlling metabolic risks.

This study had some limitations such as sample size. The data for this research were collected in medical records, which may have limited the number of information that could be relevant to the study.

\section{Conclusion}

The puberty phase increases the risk for hypovitaminosis D mainly in obese adolescents. Once this vitamin is crucial for bone health, and as it seems it is necessary to the homeostasis of glycemia, lipids, and body weight, its monitoring should be performed with rigor and caution. As our results are based in a short number of adolescents and literature is scarce on studies with individuals in pre-pubertal and pubertal stage, we suggest that more studies should be performed to confirm the precise role of vitamin $\mathrm{D}$ in the promotion and maintenance of health.

\section{Conflicts of Interest}

The authors declare no conflicts of interest regarding the publication of this paper.

\section{References}

[1] Bouillon, R. (2018) Extra-Skeletal Effects of Vitamin D. Frontiers of Hormone Research, 50, 72-88. https://doi.org/10.1159/000486072

[2] Abreu-Delgado, Y., Isidro, R.A. and Torres, E.A. (2016) Serum Vitamin D Andcolonic Vitamin D Receptor in Inflammatory Bowel Disease. World Journal of Gastroenterology, 7, 3581-3591. https://doi.org/10.3748/wjg.v22.i13.3581

[3] Kundakci, G.G., Sengul, S., Nergizoglu, G., Ertürk, S., Duman, N. and Kutlay, S. (2018) Is Sclerostin Level Associated with Cardiovascular Diseases in Hemodialysis Patients? Blood Purification, 25, 118-125.

[4] Liu, X., Baylin, A. and Levy, P.D. (2018) Vitamin D Deficiency and Insufficiency among US Adults: Prevalence, Predictors and Clinical Implications. British Journal of Nutrition, 119, 928-936. https://doi.org/10.1017/S0007114518000491

[5] Cordeiro, A., Santos, A., Bernardes, M., Ramalho, A. and Martins, M.J. (2017) Vitamin D Metabolism in Human Adipose Tissue: Could It Explain Low Vitamin D Status in Obesity? Hormone Molecular Biology and Clinical Investigation, 18, 1-9.

[6] Durá-Travé, T., Gallinas-Victoriano, F., Chueca-Guidulan, M.J. and Berrade-Zubiri, 
S. (2017) Prevalence of Hypovitaminiosis D and Associated Factors in Obese Spanish Children. Nutrition \& Diabetes, 13, 1-5.

[7] Barbalho, S.M., Tofano, R.J., de Campos, A.L., Rodrigues, A.S., Quesada, K., Bechara, M.D., de AlvaresGoulart, R. and Oshiiwa, M. (2018) Association between Vitamin D Status and Metabolic Syndrome Risk Factors. Diabetology \& Metabolic Syndrome, 16, 30032-30038. https://doi.org/10.1016/j.dsx.2018.03.011

[8] Fernándes, S.B., Aguilera, C.M., Silva, I.M., Vazquez, R., Campos, M.G. and Olza, J. (2017) 25i Hydroxyvitamin D Levels of Children Are Inversely Related to Adiposity Assessed by Body Mass Index. Journal of Physiology and Biochemistry, 25, 1-8.

[9] Khayyatzadeh, S.S., Mirmoosavi, S.J., Fezeli, M., Abasalti, Z., Avan, A. And Javandoost, A. (2017) High-Dose Vitamin D Supplementation Is Associated with an Improvement in Several Cardiometabolic Risk Factor in Adolescent Girls: Nine-Week Fallow-Up Study. Annals of Clinical Biochemistry, 1, 1-27.

[10] Tanner, J.M. (1962) Growth at Adolescence. 2nd Edition, Blackwell Scientific Publications, Oxford.

[11] Holick, M.F., Binkley, N.C., Bischoff-Ferrari, H.A. and Gordon, C.M. (2011) Evaluation, Treatment, and Prevention of Vitamin D Deficiency: An Endocrine Society Clinical Practice Guideline. The Journal of Clinical Endocrinology \& Metabolism, 96, 1911-1930. https://doi.org/10.1210/jc.2011-0385

[12] Saggese, G., Vierucci, F., Prodam, F., Cardinale, F., Cetin, I. and Chiappini, E. (2018) Vitamin D in Pediatric Age: Consensus of the Italian Pediatric Society and the Italian Society of Preventive and Social Pediatrics, Jointly with the Italian Federation of Pediatricians. Italian Journal of Pediatrics, 44, 51.

https://doi.org/10.1186/s13052-018-0488-7

[13] Cashman, K.D., Dowling, K.G., Škrabáková, Z., Gonzalez-Gross, M., Valtueña, J. and De Henauw, S. (2016) Vitamin D Deficiency in Europe: Pandemic? The American Journal of Clinical Nutrition, 103, 1033-1044. https://doi.org/10.3945/ajen.115.120873

[14] Hossain, M.J., Levinson, A., George, D., Canas, J., Kumar, S. and Balagopal, P.B. (2018) Vitamin D Status and Cardiovascular Risk in Obesity: Effect of Physical Activity in Nonvitamin D Supplemented Adolescents. Metabolic Syndrome and Related Disorders, 16, 197-203. https://doi.org/10.1089/met.2017.0171

[15] Brar, P.C., Contreras, M., Fan, X. and Visavachaipan, N. (2018) Effect of One Time High Dose "Stoss Therapy" of Vitamin D on Glucose Homeostasis in High Risk Obese Adolescents. Endocrinology and Metabolism, 62, 193-200.

[16] Laing, E.M. and Lewis, R.D. (2018) New Concepts in Vitamin D Requirements for Children and Adolescents: A Controversy Revisited. Frontiers of Hormone Research, 50, 42-65. https://doi.org/10.1159/000486065

[17] Fintini, D., Pedicelli, S., Bocchini, S., Bizzarri, C., Grugni, G. and Cappa, M. (2017) $25 \mathrm{OH}$ Vitamin D Levels in Pediatric Patients Affected by Prader-Willi Syndrome. Journal of Endocrinological Investigation, 41, 739-742.

[18] Mallard, S.R., Howe, A.S. and Houghton, L.A. (2016) Vitamin D Status and Weight Loss: A Systematic Review and Meta-Analysis of Randomized and Nonrandomized Controlled Weight-Loss Trials. The American Journal of Clinical Nutrition, 104, 1151-1159. https://doi.org/10.3945/ajcn.116.136879

[19] Chandler, P.D., Wang, L., Zhang, X., Sesso, H.D., Moorthy, M.V. and Obi, O. (2015) Effect of Vitamin D Supplementation Alone or with Calcium on Adiposity Measures: A Systematic Review and Meta-Analysis of Randomized Controlled Trials. Nutrition Reviews, 73, 577-593. https://doi.org/10.1093/nutrit/nuv012 
[20] Alghadir, A.H., Gabr, S.A. and Rizk, A.A. (2018) Physical Fitness, Adiposity, and Diets as Surrogate Measures of Bone Health in Schoolchildren: A Biochemical and Cross-Sectional Survey Analysis. Journal of Clinical Densitometry, 21, 406-419.

[21] Ongaratto, R., Rosa, K.M.D., Eloi, J.C., Epifanio, M., Marostica, P. and Pinto, L.A. (2018) Association between Hypovitaminosis D and Frequency of Pulmonary Exacerbations in Children and Adolescents with Cystic Fibrosis. Einstein (Sao Paulo), 16, eAO4143. https://doi.org/10.1590/s1679-45082018ao4143

[22] Lee, M.T., Kattan, M., Fennoy, I., Arpadi, S.M., Miller, R.L., Cremers, S., McMahon, D.J., Nieves, J.W. and Brittenham, G.M. (2018) Randomized Phase 2 Trial of Monthly Vitamin D to Prevent Respiratory Complications in Children with Sickle Cell Disease. Blood Advances, 2, 969-978.

https://doi.org/10.1182/bloodadvances.2017013979

[23] Hufnagl, J.J. (2018) Vitamin A and D in Allergy: From Experimental Animal Models and Cellular Studies to Human Disease. Allergo Journal International, 27, 72-78.

[24] Wacker, M. and Holick, M.F. (2013) Vitamin D-Effects on Skeletal and Extraskeletal Health and the Need for Supplementation. Nutrients, 5, 111-148.

https://doi.org/10.3390/nu5010111

[25] Yang, J., Tamura, R.N., Aronsson, C.A., Uusitalo, U.M., Lernmark, Å. and Rewers, M. (2017) Maternal Use of Dietary Supplements during Pregnancy Is Not Associated with Coeliac Disease in the Offspring: The Environmental Determinants of Diabetes in the Young (TEDDY) Study. British Journal of Nutrition, 117, 466-472. https://doi.org/10.1017/S0007114517000332

[26] Barbalho, S.M., Goulart, R.A. and Gasparini, R.G. (2017) Associations between Inflammatory Bowel Diseases and Vitamin D. Critical Reviews in Food Science and Nutrition, 13, 1-10. https://doi.org/10.1080/10408398.2017.1406333

[27] Feng, R., Li, Y., Li, G., Li, Z., Zhang, Y., Li, Q. and Sun, C. (2015) Lower Serum 25 (OH) D Concentrations in Type 1 Diabetes: A Meta-Analysis. Diabetes Research and Clinical Practice, 108, e71-e75. https://doi.org/10.1016/j.diabres.2014.12.008

[28] Di Nisio, A., De Toni, L., D’Addato, E., Pizzo, M.R., Sabatino, P. and Foresta, C. (2016) 25-Hydroxyvitamin D Insufficiency Discriminates Cardiovascular Risk Factors Accumulation in Peri-Pubertal Boys Undergoing Overweight Screening. Endocrine, 53, 530-537. https://doi.org/10.1007/s12020-015-0725-4

[29] Pannu, P.K., Piers, L.S., Soares, M.J., Zhao, Y. and Ansari, Z. (2017) Vitamin D Status Is Inversely Associated with Markers of Risk for Type 2 Diabetes: A Population Based Study in Victoria, Australia. PLoS ONE, 12, e0178825. https://doi.org/10.1371/journal.pone.0178825

[30] Thorsen, S.U., Pipper, C.B., Johannesen, J., Mortensen, H.B., Pociot, F. and Svensson, J. (2018) Danish Case-Control Study of Newly Diagnosed Patients with Childhood Type 1 Diabetes and Their Healthy Siblings. Scandinavian Journal of Immunology, 87, 46-53. https://doi.org/10.1111/sji.12632

[31] Thorsen, S.U., Mårild, K., Olsen, S.F., Holst, K.K., Tapia, G., Granström, C. and Stene, L.C. (2017) Maternal and Neonatal Vitamin D Status Are Not Associated with Risk of Childhood Type 1 Diabetes: A Scandinavian Case-Cohort Study. American Journal of Epidemiology, 187.

[32] Savastano, S., Barrea, L., Savanelli, M.C., Nappi, F., Di Somma, C. and Orio, F. (2017) Low Vitamin D Status and Obesity: Role of Nutritionist. Reviews in Endocrine and Metabolic Disorders, 18, 215-225. https://doi.org/10.1007/s11154-017-9410-7

[33] Gul, A., Özer, S., Yilmaz, R., Sönmezgöz, E., Kasap, T. and Takci, S. (2017) Associa- 
tion between Vitamin D Levels and Cardiovascular Risk Gactor in Obese Children and Adolescents. Nutrición Hospitalaria, 34, 323-329.

https://doi.org/10.20960/nh.412

[34] Sriram, S., Croghan, I., Lteif, A., Donelan-Dunlap, B., Li, Z. and Kumar, S. (2016) Relação entre $25(\mathrm{OH})$ D e lipídios circulantes em adolescentes afro-americanos. Journal of Pediatric Endocrinology and Metabolism, 29, 1-8.

[35] Prodam, F., Zanetta, S., Ricotti, R., Marolda, A., Giglione, E. and Monzani, A. (2016) Influence of Ultraviolet Radiation on the Association between 25-Hydroxy Vitamin D Levels and Cardiovascular Risk Factors in Obesity. Journal of Pediatrics, 171, 83-89.

[36] Fan, L., Zhang, Y., Zhu, J., Song, Y. and Lin, J. (2018) Association of Vitamin D Deficiency with Diabetic Peripheral Neuropathy and Diabetic Nephropathy in Tianjin, China. Asia Pacific Journal of Clinical Nutrition, 27, 599-606.

[37] Upreti, V., Maitri, V., Dhull, P., Handa, A., Prakash, M.S. and Behl, A. (2018) Effect of Oral Vitamin D Supplementation on Glycemic Control in Patients with Type 2 Diabetes Mellitus with Coexisting Hypovitaminosis D: A Parellel Group Placebo Controlled Randomized Controlled Pilot Study. Diabetes \& Metabolic Syndrome, 12, 509-512.

[38] Nader, N.S., Aguirre Castaneda, R., Wallace, J., Singh, R., Weaver, A. and Kumar, S. (2014) Effect of Vitamin D3 Supplementation on Serum 25(OH)D, Lipids and Markers of Insulin Resistance in Obese Adolescents: A Prospective, Randomized, Placebo Controlled Pilot Trial. Hormone Research in Paediatrics, 82, 107-112. https://doi.org/10.1159/000362449

[39] Jamka, M., Woźniewicz, M., Jeszka, J., Mardas, M., Bogdański, P. and Stelmach-Mardas, M. (2015) The Effect of Vitamin D Supplementation on Insulin and Glucose Metabolism in Overweight and Obese Individuals: Systematic Review with Meta-Analysis. Scientific Reports, 5, Article No. 16142.

https://doi.org/10.1038/srep16142

[40] Jamka, M., Woźniewicz, M., Walkowiak, J., Bogdański, P., Jeszka, J. And Stelmach-Mardas, M. (2016) The Effect of Vitamin D Supplementation on Selected Inflammatory Biomarkers in Obese and Overweight Subjects: A Systematic Review with Meta-Analysis. European Journal of Nutrition, 55, 2163-2176. https://doi.org/10.1007/s00394-015-1089-5

[41] Vélez, R.R., Hermoso, A.G., Sobrinho, C.A., Mota, J., Santos, R. and Bautista, J.E.C. (2017) Pubertal Stage, Body Mass Index, and Cardiometabolic Risk in Children and Adolescents in Bogatá, Colombia: The Cross-Sectional Fuprecol Study. Nutrients, 9, 644.

[42] Paller, A.S., Hawk, J.L., Honig, P., Giam, Y.C., Hoath, S., Mack, M.C. and Stamatas, G.N. (2011) New Insights about Infant and Toddler Skin: Implications for Sun Protection. Pediatrics, 128, 92-102. https://doi.org/10.1542/peds.2010-1079

[43] Vierucci, F., Del Pistoia, M., Fanos, M., Erba, P. and Saggese, G. (2014) Prevalence of Hypovitaminosis D and Predictors of Vitamin D Status in Italian Healthy Adolescents. Italian Journal of Pediatrics, 40, 54.

[44] Society for Adolescent Health and Medicine (2013) Recommended Vitamin D Intake and Management of Low Vitamin D Status in Adolescents: A Position Statement of the Society for Adolescent Health and Medicine. Journal of Adolescent Health, 52, 801-803. https://doi.org/10.1016/j.jadohealth.2013.03.022 